\title{
Geosynthetic landfill cap stability: comparison of limit equilibrium, computational limit analysis and finite- element analyses
}

\author{
E. B. Belczyk ${ }^{1}$ and C. C. Smith ${ }^{2}$ \\ ${ }^{1}$ Geotechnical Engineer, Mott MacDonald Ltd, Geotechnical Division, Mott MacDonald House, 111 St \\ Mary's Rd, S24AP, Sheffield, UK, Telephone: +44 (0) 114276 1248; Telefax: +44 (0) 1142724699 ; \\ E-mail: emilia.belczyk@mottmac.com \\ ${ }^{2}$ Senior Lecturer, Department of Civil and Structural Engineering, University of Sheffield, Sir Frederick \\ Mappin Building, Mappin Street, S1 3JD, Sheffield, UK, Telephone: +44 (0) 114222 5717; Telefax: \\ +44 (0) 114222 5700; E-mail: c.c.smith@sheffield.ac.uk
}

Received 16 October 2010, revised 9 December 2011, accepted 27 January 2012

\begin{abstract}
The stability of the veneer cover soil (landfill cap) is an important issue in landfill design. Incorrect design of the landfill cap can lead to failure, which may result in the veneer cover soil sliding on an underlying geosynthetic layer, or in tension failure of the geosynthetic itself. Previous limit equilibrium (LE) analyses of veneer cover layer stability presented in the literature have generally considered whole-slope failure. In this paper, modified LE equations are proposed that (a) encompass more critical cases of localised slope failure for specific cases, and (b) are calibrated against two other methods: 2-D computational limit analysis (CLA) using LimitState:GEO and 2-D elasto-plastic finite-element (FE) analysis using PLAXIS. The scenarios examined encompass a cover of uniform thickness, a buttressed cover, a cover of tapered thickness, the effects of seepage forces, and the effects of construction equipment. It is shown that the LE method provides a reasonable estimate of veneer cover layer stability for most cases examined, although it is in general non-conservative, relative to the CLA and FE analyses. Local failure was found to be critical in the case of the construction equipment, buttress and horizontal seepage scenarios. In the latter case the LE equations previously presented in the literature significantly overestimate stability compared with the LE, CLA and FE analyses considered in this paper.
\end{abstract}

KEYWORDS: Geosynthetics, Veneer cover, Landfill Cap, Slope stability, Limit equilibrium method, Computational limit analysis, Finite-element method

REFERENCE: Belczyk E. B. \& Smith, C. C. (2012). Geosynthetic landfill cap stability: comparison of limit equilibrium, computational limit analysis and finite-element analyses. Geosynthetics International, 19, No. 2, 133-146. [http://dx.doi.org/10.1680/gein.2012.19.2.133]

\section{INTRODUCTION}

\subsection{Background and aims}

Landfill caps often consist of a thin veneer of cover soil placed on top of a geosynthetic layer. This arrangement can cause several problems in landfill engineering, including sliding of the veneer cover soil on the geosynthetic-lined slope, and tension failure of the geosynthetic itself. It is therefore very important to choose an appropriate method of design, and determine soil and interface parameters accurately, when designing veneer cover soil. The aims of this paper are to reexamine the limit equilibrium (LE) analyses available in the literature for veneer cover sliding, to propose updated formulations, and to calibrate these against results from the computational limit analysis (CLA) and finite- element (FE) approaches in order to establish the limits of their validity.

\subsection{Previous and proposed work}

Limit equilibrium analyses of this problem have been presented by Giroud and Beech (1989), Koerner and Hwu (1991), Soong and Koerner (1996), Jones and Dixon (1998), Koerner and Soong (2005) and Koerner (2005). In Giroud and Beech's paper the slope was divided into two wedges. The interwedge forces were balanced in the vertical and horizontal directions, and an iterative process was used to determine the factor of safety (FoS) using the obtained equations. Koerner and Hwu also based their analysis on the two-wedge method. They assumed sliding to be resisted by only the shear strength along the interface, and that the FoS is the same at every point of 
the sliding surface. However, they did not consider the effect of seepage forces on the stability of the veneer cover soil. A model incorporating the effect of seepage downslope (parallel to the slope) and horizontal was presented by Soong and Koerner (1996).

The papers by Koerner and Soong (2005) and Koerner (2005) are typical of those in the literature, and will be used as a basis for the present work. The former paper presents analyses of veneer cover soil stability using the LE method for a range of different scenarios, such as a cover of uniform thickness, a buttressed cover, a cover of tapered thickness, the effects of horizontal and parallel seepage forces, and the effects of construction equipment. The analysis generally assumes a two-part wedge failure, involving a long, thin, active wedge along the slope length, with a tension crack at the crest and small passive wedge near the toe of the slope. In the second paper, Koerner repeated the original LE analysis for a cover of uniform thickness and tapered thickness using a more detailed description of the calculations.

A key feature of the Koerner and Soong LE solutions is that they assume failure of the entire slope. Initial comparisons with numerical analyses indicated that this is not necessarily the most critical mechanism in all cases. This paper therefore proposes modified versions of Koerner and Soong's equations that consider the more critical occurrence of localised failure and a more general treatment of seepage effects. The original and modified equations are compared with CLA using LimitState:GEO and FE analysis using PLAXIS. Two analyses are carried out using CLA: (1) a 'forced' analysis, in which the model is constrained to represent the exact LE problem, including all implicit assumptions; and (2) a 'standard' (optimal) analysis, in which the software analyses the critical collapse mechanism. The former allows cross-validation of the LE and CLA analyses. The advantages and disadvantages of the three approaches are examined.

\subsection{Analysis methods}

\subsubsection{Limit equilibrium method}

The most commonly used geotechnical engineering approaches to slope stability problems are LE methods. The LE concept generally involves an assumed collapse mechanism and subsequent analysis of the equilibrium of this mechanism. It typically involves assumptions regarding stress conditions and/or mechanism kinematics. Its key advantages are its simplicity and clarity; however, disadvantages are that it may not cover the most critical collapse mode, and its status (upper or lower bound) is not defined.

\subsubsection{Limit analysis method}

The limit analysis method is based on the application of plasticity theory to give either an upper or a lower bound to the collapse load. The upper-bound mechanism approach is similar to LE, but requires rigorous application of plasticity principles. In this paper the discontinuity layout optimisation (DLO) method as implemented in the CLA software (LimitState:GEO Manual; LimitState Ltd 2009 ) is adopted. In the DLO approach numerical optimi- sation is used to identify the optimal upper-bound collapse mechanism directly and closely.

As its name suggests, DLO is concerned with identifying the optimal layout of discontinuities (i.e. slip-lines in a geotechnical stability problem) that make up a failure, or critical mechanism. The associated collapse load gives an upper bound to the collapse load for the construction. In effect, the procedure replicates and automates the traditional upper-bound hand limit analysis procedure used in geotechnics (Smith and Gilbert 2007).

\subsubsection{Finite-element method}

In this paper the FE program PLAXIS 2D Version 9.0 was used (PLAXIS Manual; Brinkgreve et al. 2008). PLAXIS is a program used in geotechnical analysis that uses elasto-plastic models to simulate soil behaviour. In order to determine collapse loads, the analysis uses an incremental multiplier $\Sigma M s f$ to specify the increment of the strength reduction. The strength parameters are successively reduced automatically. A large number of additional steps (typically 100) are required to ensure a solution. This $\phi^{\prime}-\mathrm{c}^{\prime}$ reduction approach resembles the method of obtaining the FoS as conventionally adopted in slip-circle analysis (where $c^{\prime}$ is a drained cohesion intercept of the cover soil and other materials, and $\phi^{\prime}$ is an angle of shearing resistance of the cover soil).

\section{LIMIT EQUILIBRIUM ANALYSIS}

\subsection{Introduction}

The analyses presented in this paper are modifications of those presented by Koerner and Soong (2005) and Koerner (2005). The Koerner and Soong (2005) model geometry considered a number of scenarios under which the instability of the veneer cover soil may be assessed:

- uniform thickness veneer cover soil;

- $\quad$ veneer cover soil with construction equipment;

- $\quad$ seepage forces parallel to the slope;

- $\quad$ seepage forces horizontal to the slope;

- $\quad$ veneer cover soil with buttresses; and

- veneer cover soil with tapered thickness.

In this paper, modified versions of the analyses are presented for each case, and are compared with the original Koerner and Soong equations. The general approach to the analysis is first presented in Section 2.2 to illustrate the basic assessment model for all cases. Modified and slightly simplified versions of the uniform cover layer and tapered thickness cover soil models are presented in Sections 2.3 and 2.7. Modified versions of the seepage forces analysis, construction equipment and buttresses analyses that consider the more critical case of localised failure are presented in Sections 2.4, 2.5 and 2.6.

\subsection{General analysis approach}

The general analysis approach considers a two-wedge mechanism and the equilibrium of forces acting on each wedge, including water pressures. This is presented here, 
with commentary to bring out the key features of the analysis. Each specific scenario outlined in Section 2.1 is represented by this generic form, and simply varies the magnitude of forces acting. Equations for these forces will be presented for each scenario in Sections 2.3-2.7. The basic geometry of the uniform cover soil problem is presented in Figure 1. The symbols used in Figure 1 are defined as follows: $W_{\mathrm{A}}$ is the total weight of the active wedge; $W_{\mathrm{P}}$ is the total weight of the passive wedge; $N_{\mathrm{A}}^{\prime}$ is the effective force normal to the failure plane of the active wedge; $N_{\mathrm{P}}^{\prime}$ is the effective force normal to the failure plane of the passive wedge; $C_{\mathrm{A}}$ is the cohesive shear force between the cover soil of the active wedge and the geomembrane; $C_{\mathrm{P}}$ is the cohesive shear force along the failure plane of the passive wedge; $U_{\mathrm{a}}$ is the resultant of the pore pressure acting on the vertical crest at the crest of the slope; $U_{\mathrm{h}}$ is the resultant of the pore pressure acting on the interwedge surfaces; $U_{\mathrm{n}}$ is the resultant of the pore pressure acting perpendicular to the slope; $U_{\mathrm{V}}$ is the resultant of the vertical pore pressure acting on the passive wedge; $\gamma$ is the dry unit weight of the cover soil and other materials; $c^{\prime}$ is the drained cohesion intercept of the cover soil and other materials; $c_{\mathrm{a}}^{\prime}$ is the drained adhesion intercept between the cover soil of the active wedge and the geomembrane; $\delta^{\prime}$ is the interface friction angle between cover soil and geosynthetic; $\phi^{\prime}$ is the angle of shearing resistance of the cover soil; $\beta$ is the soil slope angle beneath the geomembrane; $h$ is the thickness of the cover soil; $L$ is the length of slope measured along the geomembrane; $L_{\mathrm{g}}$ is the length of slope involved in LE mechanism measured along the geomembrane; $E_{\mathrm{A}}^{\prime}$ is the effective interwedge force acting on the active wedge from the passive wedge; and $E_{\mathrm{P}}^{\prime}$ is the effective interwedge force acting on the passive wedge from the active wedge.

The length of the slope, $L_{\mathrm{g}}$, is used in the following analysis for convenience rather than $L$, which was used by Koerner and Soong (2005), but is only indirectly related to the assumed failure mechanism.

Koerner and Soong (2005) calculated the FoS by treating the passive and active wedges as free bodies with the forces applied as illustrated, and by balancing the interwedge forces.
Key assumptions made in the LE analysis are as follows.

1. The active and passive wedges are separated by a vertical interface.

2. The resultant forces acting on the vertical interface are oriented parallel to the main slope. If sliding were to be occurring along this interface, then the forces on this interface should be modelled mobilising full friction and cohesion. However, this leads to significant additional complication in the equations, and is not necessarily justified, owing to assumption 1. In effect the assumption is that $c_{\text {mob }}^{\prime}=0$ and $\phi_{\text {mob }}^{\prime}=\beta$ on the interface (where $\beta$ is the slope angle, and mob denotes the mobilised strength parameter), which would be generally conservative.

3. At the top of the active wedge, a tension crack is assumed so that no soil forces act on this boundary, maintaining the simplicity of the solution. The assumed orientation of the tension crack may vary between different LE analyses. However, for relatively thin cover layers the orientation of the crack has little influence on the final stability assessment.

4. The FoS is applied only to shearing along the geomembrane and shearing along the base of the passive wedge.

5. Water pressures (where present) act across and normal to the interfaces.

The effective normal force acting on the geomembrane can be determined as

$$
N_{\mathrm{A}}^{\prime}=W_{\mathrm{A}} \cos \beta+\left(U_{\mathrm{h}}-U_{\mathrm{a}}\right) \sin \beta-U_{\mathrm{n}}
$$

The effective interwedge force $E_{\mathrm{A}}^{\prime}$ acting on the active wedge can be expressed as

$$
E_{\mathrm{A}}^{\prime}=W_{\mathrm{A}} \sin \beta-\frac{N_{\mathrm{A}}^{\prime} \tan \delta^{\prime}+C_{\mathrm{A}}}{\mathrm{FoS}}-\left(U_{\mathrm{h}}-U_{\mathrm{a}}\right) \cos \beta
$$

Horizontal equilibrium of the passive wedge gives

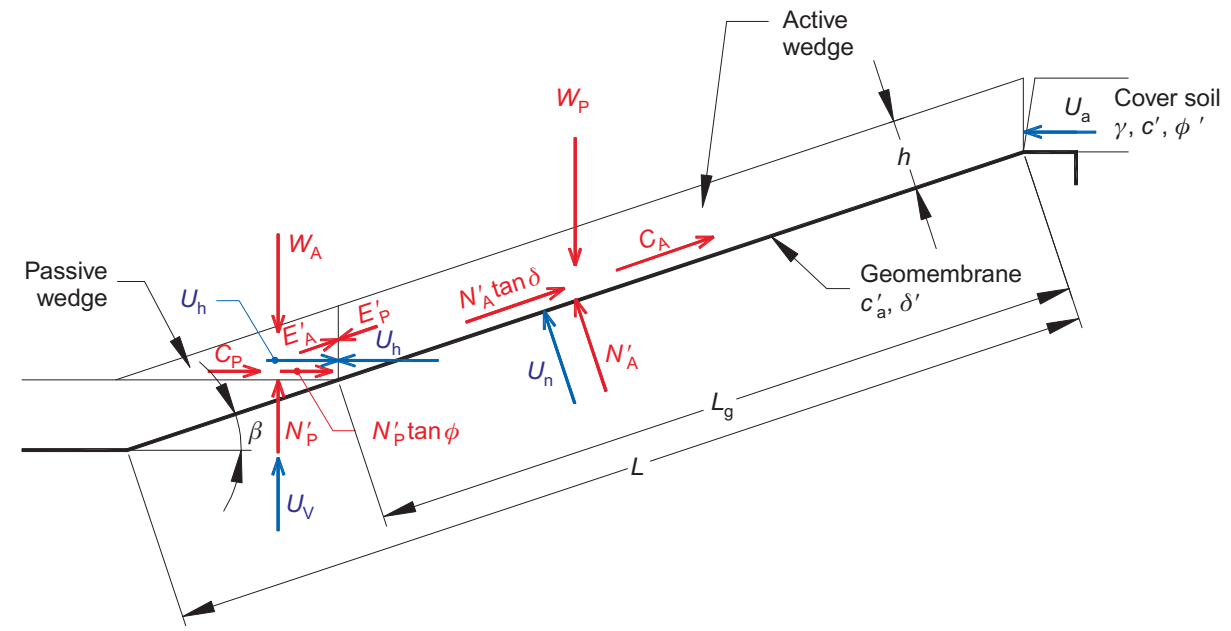

Figure 1. Limit equilibrium of forces for general analysis form (after Koerner and Soong 2005). 


$$
E_{\mathrm{P}}^{\prime} \cos \beta+U_{\mathrm{h}}=\frac{N_{\mathrm{P}}^{\prime} \tan \phi^{\prime}+C_{\mathrm{P}}}{\mathrm{FoS}}
$$

and vertical equilibrium gives

$$
E_{\mathrm{P}}^{\prime} \sin \beta+W_{\mathrm{P}}=N_{\mathrm{P}}^{\prime}+U_{\mathrm{V}}
$$

From the horizontal and vertical equilibrium of the passive wedge, the interwedge force $E_{\mathrm{P}}^{\prime}$ acting on the passive wedge can be expressed as

$$
E_{\mathrm{P}}^{\prime}=\frac{C_{\mathrm{P}}+\left(W_{\mathrm{P}}-U_{\mathrm{V}}\right) \tan \phi^{\prime}-U_{\mathrm{h}} \times \mathrm{FoS}}{\cos \beta \times \mathrm{FoS}-\sin \beta \tan \phi^{\prime}}
$$

By equating $E_{\mathrm{A}}^{\prime}$ and $E_{\mathrm{P}}^{\prime}$, it is possible to obtain a resulting equation of the form

$$
a(\mathrm{FoS})^{2}+b(\mathrm{FoS})+c=0
$$

from which the FoS can be calculated for all scenarios described in this paper. The parameters $a, b$ and $c$ are defined as follows.

$$
\begin{aligned}
a= & W_{\mathrm{A}} \sin \beta \cos \beta-\left(U_{\mathrm{h}}-U_{\mathrm{a}}\right) \cos ^{2} \beta+U_{\mathrm{h}} \\
b= & -\cos \beta\left(N_{\mathrm{A}}^{\prime} \tan \delta^{\prime}+C_{\mathrm{A}}\right) \\
& \quad-\tan \phi^{\prime}\left[W_{\mathrm{A}} \sin ^{2} \beta+W_{\mathrm{P}}-U_{\mathrm{V}}-\sin \beta \cos \beta\right. \\
& \left.\quad \times\left(U_{\mathrm{h}}-U_{\mathrm{a}}\right)\right]-C_{\mathrm{P}} \\
c= & \sin \beta \tan \phi\left(N_{\mathrm{A}}^{\prime} \tan \delta^{\prime}+C_{\mathrm{A}}\right)
\end{aligned}
$$

The final form of FoS is in the form of a quadratic equation, and is obtained from

$$
\mathrm{FoS}=\frac{-b \pm \sqrt{b^{2}-4 a c}}{2 a}
$$

Normally, it is found that taking the positive square root in Equation 10 gives the required solution. However, it is advisable to check both possible solutions.

\subsection{Uniform veneer cover layer}

The basic geometry of the uniform cover soil problem is given in Figure 1, with all water forces $U$ taken as zero.

At the top of the active wedge, a tension crack is assumed. For a cohesionless soil this is unconservative, in that there will be an additional small secondary active wedge failure at this point. However, inclusion of the small wedge in the analyses introduces significant additional complexity into the equations, with negligible change to the overall stability assessment (it can easily be shown that the pressure on the main active wedge cannot be more than the weight of the small secondary wedge, and that this is comparatively small if the length/thickness of the cover layer is large). Hence assumption of an effectively pressure free vertical boundary (tension crack or edge of small wedge) retains simplicity. In the proposed analysis the crack is assumed to be vertical (following e.g. Jones and Dixon 1998). This introduces an additional downslope force and a small reduction in the nonconservatism of the analysis, compared with the assumption of a tension crack normal to the slope by Koerner and Soong (2005).
Key parameters to be used in the generic equation are given in Table 1.

\subsection{Influence of seepage}

There are situations when adequate drainage of veneer covers is sometimes not available, and a build-up of seepage forces or pore pressures may occur. The following two scenarios considered in this paper are idealisations/ simplifications of the real seepage state that may occur on the slope:

- $\quad$ Flow initiates part way down the slope, and builds up to a fixed depth $h_{\mathrm{w}}$ perpendicular to the slope (Figure 2a).

- Flow initiates at the top of the slope behind the crest, and flows downslope (Figure 2b).

In both cases it is assumed that the critical collapse mechanism initiates from the point at which the phreatic surface starts to run parallel to the slope, and that a vertical crack opens up (or a small secondary active wedge forms) that passes through this point, as shown in Figure 3. This hypothesis will be cross-checked later using the

Table 1. Parameters for uniform cover layer (all water forces, $U$, are zero)

\begin{tabular}{|l|l|l|}
\hline Parameter & Koerner and Soong (2005) & Proposed equation \\
\hline$W_{\mathrm{A}}$ & $\gamma h^{2}\left(\frac{L_{\mathrm{g}}}{h}-\frac{\tan \beta}{2}\right)$ & $\gamma h L_{\mathrm{g}}$ \\
$C_{\mathrm{A}}$ & $c_{\mathrm{a}}^{\prime} L_{\mathrm{g}}$ & $c_{\mathrm{a}}^{\prime} L_{\mathrm{g}}$ \\
$W_{\mathrm{P}}$ & $\frac{\gamma h^{2}}{\sin (2 \beta)}$ & $\frac{\gamma h^{2}}{\sin (2 \beta)}$ \\
$C_{\mathrm{P}}$ & $\frac{c^{\prime} h}{\sin \beta}$ & $\frac{c^{\prime} h}{\sin \beta}$ \\
\hline
\end{tabular}

Note that the original Koerner and Soong equations were expressed in terms of the inclined length of the geosynthetic, $L$, where $L_{\mathrm{g}}=L-h / \sin \beta$.

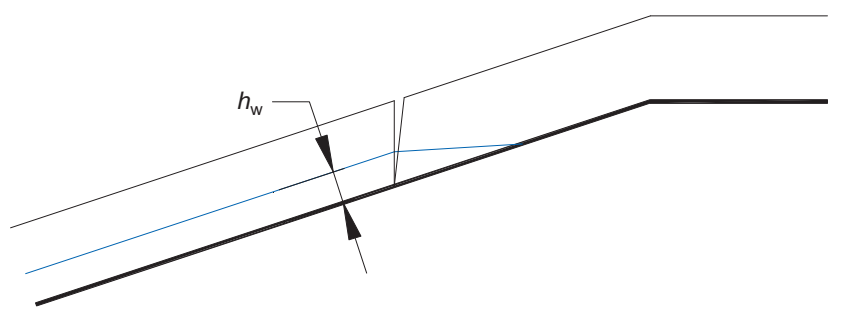

(a)

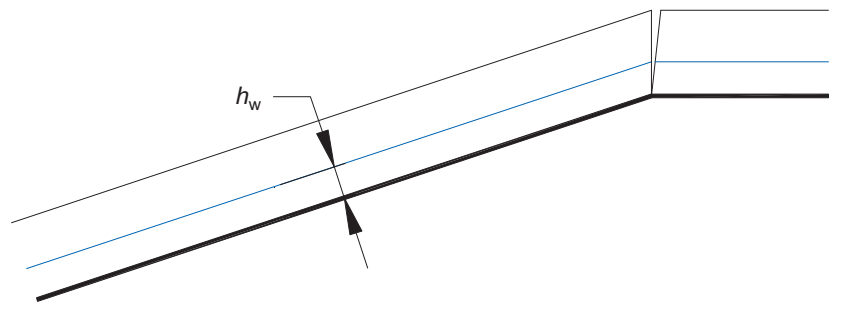

(b)

Figure 2. Seepage scenarios: (a) flow build-up on slope (b) flow initiates at top of slope 


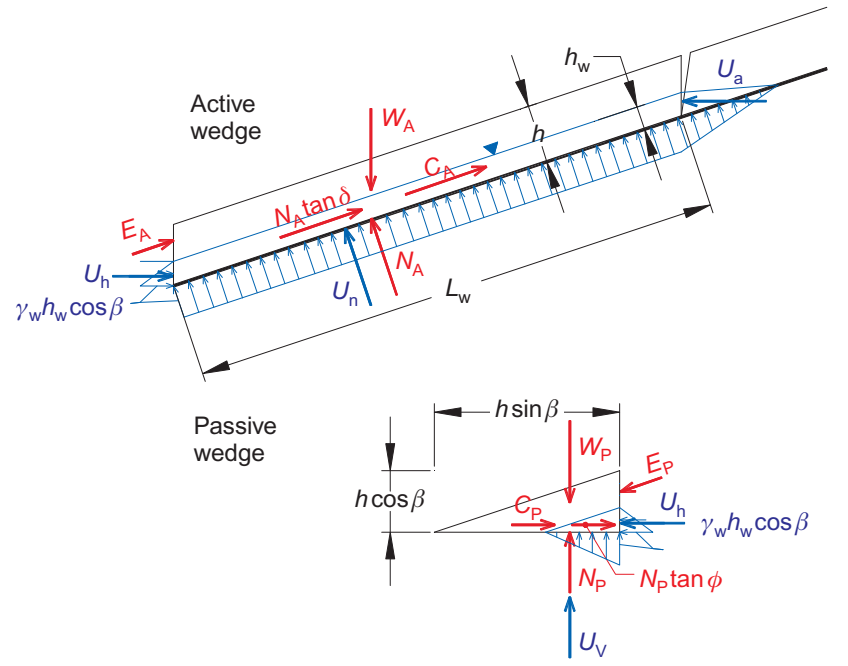

Figure 3. Limit equilibrium of forces for a cover soil with seepage build-up parallel to slope

numerical CLA and FE analysis methods. Thus both cases can be modelled using the same analytical model shown in Figure 3. With correct choice of parameters this model can also represent the types of seepage condition considered by Koerner and Soong (parallel and horizontal seepage build-up). However, Koerner and Soong considered that in the case of horizontal seepage build-up the collapse involves the whole slope, which can be shown to be less critical than the above assumption. Assumption of a whole-slope failure would typically give rise to significant tensile forces between the upper (dry) and lower (saturated) portions of the slope, which is mechanically unreasonable. The equations for determination of the key parameters in the stability analysis are presented in Table 2 , where $\gamma_{\mathrm{s}}$ is the saturated unit weight of the cover soil; $\gamma_{\mathrm{w}}$ is the unit weight of water; $H_{\mathrm{w}}$ is the vertical height of the free water surface measured from the toe; $H$ is the vertical height of the slope measured from the toe; $h_{\mathrm{w}}$ is the height of the free water surface measured in the direction perpendicular to the slope; and $L_{w}$ is the length of slope involved in the LE mechanism under the free water surface.
Koerner and Soong (2005) considered what they termed horizontal and parallel submergence ratios, HSR and PSR, respectively. The analyses show that the FoS decreases with increasing submergence ratio. These can be represented in the present model by $\left(h_{\mathrm{w}}=\mathrm{PSR} h, L_{\mathrm{w}}=L_{\mathrm{g}}\right)$ and $\left(h_{\mathrm{w}}=h, L_{\mathrm{w}}=\mathrm{HSR} L_{\mathrm{g}}\right)$, respectively. In the current analyses, HSR $=$ PSR $=0.5$. However, the most severe scenario might be expected to involve blockage of a drainage layer at its base and build-up of pore water pressure along the whole length of the slope such that $h_{\mathrm{w}}>h$ at the base of the slope (assuming the drainage layer permeability is significantly higher than that of the cover layer).

\subsection{Construction equipment forces}

Koerner and Soong (2005) considered two scenarios when analysing the cover soil with construction equipment forces:

- equipment backfilling upslope (accelerating upslope); and

- equipment backfilling downslope (accelerating downslope).

However, the second scenario was not recommended by Koerner and Soong, because this method of placing the soil would involve a low FoS due to lack of supporting fill downslope. Whereas Koerner and Soong (2005) presented an analysis based on a whole-slope failure, and considered downslope equipment acceleration more critical, in this paper it is shown that upslope equipment acceleration coupled with consideration of a localised failure leads to more critical failure scenario. The analysis model is depicted in Figure 4.

The corresponding equations are derived as follows for a vehicle of mass $M$ per unit width, and length $l$.

$$
\begin{aligned}
& L_{\mathrm{c}}=l+h \tan \beta \\
& T-W \sin \beta=M a \\
& W=M g \\
& T=M(a+g \sin \beta) \\
& N^{\prime}=W \cos \beta
\end{aligned}
$$

Table 2. Parameters for seepage conditions

\begin{tabular}{|l|l|l|l|}
\hline Parameter & Koerner and Soong (2005) horizontal seepage & Koerner and Soong (2005) parallel seepage & Proposed equation \\
\hline$W_{\mathrm{A}}$ & $\frac{\gamma_{\mathrm{s}} h}{\sin 2 \beta}\left(2 H_{\mathrm{w}} \cos \beta-h\right)+\frac{\gamma h}{\sin \beta}\left(H-H_{\mathrm{w}}\right)$ & $\frac{\gamma_{\mathrm{s}} h_{\mathrm{w}}}{\sin 2 \beta}\left(2 H \cos \beta-h_{\mathrm{w}}\right)+\frac{\gamma\left(h-h_{\mathrm{w}}\right)}{\sin 2 \beta}\left[2 H \cos \beta-\left(h-h_{\mathrm{w}}\right)\right]$ & {$\left[\gamma_{\mathrm{s}} h_{\mathrm{w}}+\gamma\left(h-h_{\mathrm{w}}\right)\right] L_{\mathrm{w}}$} \\
$U_{\mathrm{a}}$ & 0 & 0 & $\frac{\gamma_{\mathrm{w}} h_{\mathrm{w}}^{2}}{2}$ \\
$U_{\mathrm{h}}$ & $\frac{\gamma_{\mathrm{w}} h^{2}}{2}$ & $\frac{\gamma_{\mathrm{w}} h_{\mathrm{w}}^{2}}{2}$ & $\frac{\gamma_{\mathrm{w}} h_{\mathrm{w}}^{2}}{2}$ \\
$U_{\mathrm{n}}$ & $\frac{\gamma_{\mathrm{w}} h \cos \beta}{\sin 2 \beta}\left(2 H_{\mathrm{w}} \cos \beta-h\right)$ & $\frac{\gamma_{\mathrm{w}} h_{\mathrm{w}} \cos \beta}{\sin 2 \beta}\left(2 H \cos \beta-h_{\mathrm{w}}\right)$ & $\gamma_{\mathrm{w}} h_{\mathrm{w}} L_{\mathrm{w}} \cos \beta$ \\
$C_{\mathrm{A}}$ & $\frac{c_{\mathrm{a}}^{\prime} L_{\mathrm{g}}}{\gamma_{\mathrm{a}}^{\prime} L_{\mathrm{g}}}$ & $\frac{\gamma\left(h^{2}-h_{\mathrm{w}}^{2}\right)+\gamma_{\mathrm{s}} h_{\mathrm{w}}^{2}}{\sin 2 \beta}$ & $\left.\frac{\gamma^{\prime} L_{\mathrm{w}}}{2}-h_{\mathrm{w}}^{2}\right)+\gamma_{\mathrm{s}} h_{\mathrm{w}}^{2}$ \\
$W_{\mathrm{P}}$ & $\frac{\gamma_{\mathrm{s}} h^{2}}{\sin 2 \beta}$ & $\frac{U_{\mathrm{h}}}{\tan \beta}$ & $\frac{U_{\mathrm{h}}}{\tan \beta}$ \\
$U_{\mathrm{v}}$ & $\frac{U_{\mathrm{h}}}{\tan \beta}$ & $\frac{c^{\prime} h}{\sin \beta}$ & $\frac{c^{\prime} h}{\sin \beta}$ \\
$C_{\mathrm{P}}$ & $\frac{c^{\prime} h}{\sin \beta}$ &
\end{tabular}




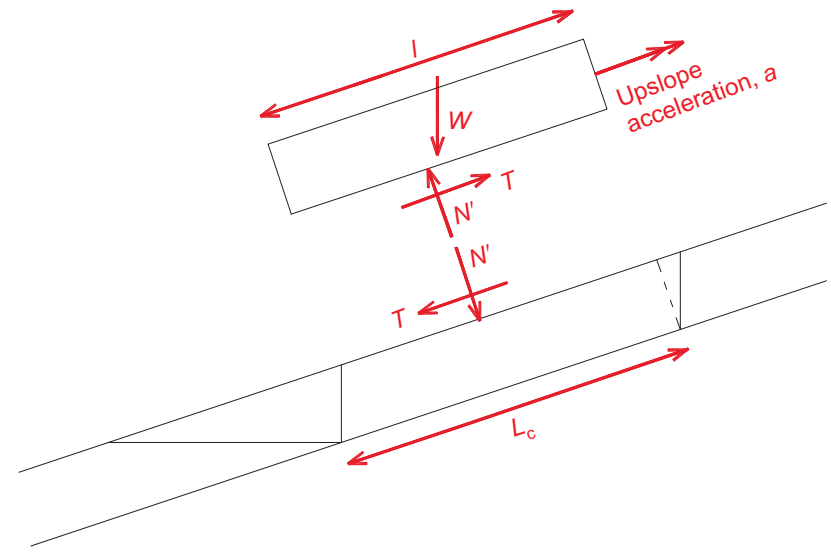

Figure 4. Limit equilibrium of forces for construction equipment moving up a slope

where $N^{\prime}$ is the effective normal force; $T$ is the effective shear force between construction equipment and cover fill; $a$ is the upslope equipment acceleration; $L_{\mathrm{c}}$ is the length of slope involved in the LE mechanism under construction equipment; and $l$ is the length of construction equipment.

The analysis then proceeds as for the uniform thickness cover layer with $L_{\mathrm{g}}=L_{\mathrm{c}}$, and with the modifications in Table 3, where $W_{\mathrm{A}}$ is set to the weight of the active wedge plus the weight $(W)$ of the construction equipment, and additionally the $W_{\mathrm{A}} \sin \beta$ term in Equation 2 becomes $W_{\mathrm{A}} \sin \beta+M a$.

For the equipment backfilling it is possible that local

\section{Table 3. Parameters for construction equipment}

\begin{tabular}{|l|l|l|}
\hline Parameter & Koerner and Soong (2005) & Proposed equation \\
\hline$W_{\mathrm{A}}{ }^{\mathrm{a}}$ & $\gamma h^{2}\left(\frac{L_{\mathrm{g}}}{h}-\frac{\tan \beta}{2}\right)$ & $\gamma h L_{\mathrm{c}}+W$ \\
$C_{\mathrm{A}}$ & $c_{\mathrm{a}}^{\prime}\left(L_{\mathrm{g}}-\frac{h}{\tan \beta}\right)$ & $c_{\mathrm{a}}^{\prime} L_{\mathrm{c}}$ \\
$W_{\mathrm{P}}$ & $\frac{\gamma h^{2}}{\sin (2 \beta)}$ & $\frac{\gamma h^{2}}{\sin (2 \beta)}$ \\
$C_{\mathrm{P}}$ & $\frac{c^{\prime} h}{\sin \beta}$ & $\frac{c^{\prime} h}{\sin \beta}$ \\
\hline
\end{tabular}

${ }^{a}$ In this case this value is equivalent in effect to the weight of the active wedge. All water forces, $U$, are zero. failure could occur under each track. This will depend on the thickness of the soil layer. In this analysis a conservative plane-strain analysis is carried out for each track. In reality, failure will involve additional out-of-plane resistances.

\subsection{Toe buttress}

In the analysis presented by Koerner and Soong (2005), the collapse mechanism was assumed to involve a combination of the whole slope and the toe buttress. However, as shown by Koerner and Soong (2005), it can be demonstrated that a more critical mechanism will typically involve failure either of the upper slope only above the buttress, or of the buttress only, depending on which is longer. In either case the situation can be represented by the uniform cover thickness analysis using the appropriate length $\left(L_{1}\right.$ or $\left.L_{2}\right)$ from Figure 5 (although a low-level buttress analysis requires additional modification). Use of the uniform cover analysis for the buttress layer does require the assumption of a 'tension crack' or negligible small secondary active wedge at the upper boundary of the wedge of length $\mathrm{L}_{1}$ in Figure 5. For a thick or lowlevel buttress this assumption has reduced viability, and leads to a more complex analysis that is beyond the scope of this paper. However, such situations are easily handled by the numerical methods, and comparisons with the LE analysis are made in Section 6.2.

Both lengths should be considered, and the most critical case chosen. Modified parameters are given in Table 4, where $h_{1}$ is the thickness of the lower active wedge of the toe buttress; $h_{2}$ is the thickness of the upper active wedge of the toe buttress; $L_{1}$ is the length of the lower active wedge of the toe buttress; $L_{2}$ is the length of the upper active wedge of the toe buttress; $x$ is the width of the toe berm; and $y$ is the height of the toe berm.

Koerner and Soong's analysis also includes

$$
h_{1}=x \sin \beta+h_{2}
$$

\subsection{Tapered cover layer}

In this case it is expected that the collapse will involve the full length of the slope, and the analysis will closely match that given by Koerner and Soong (2005), with the

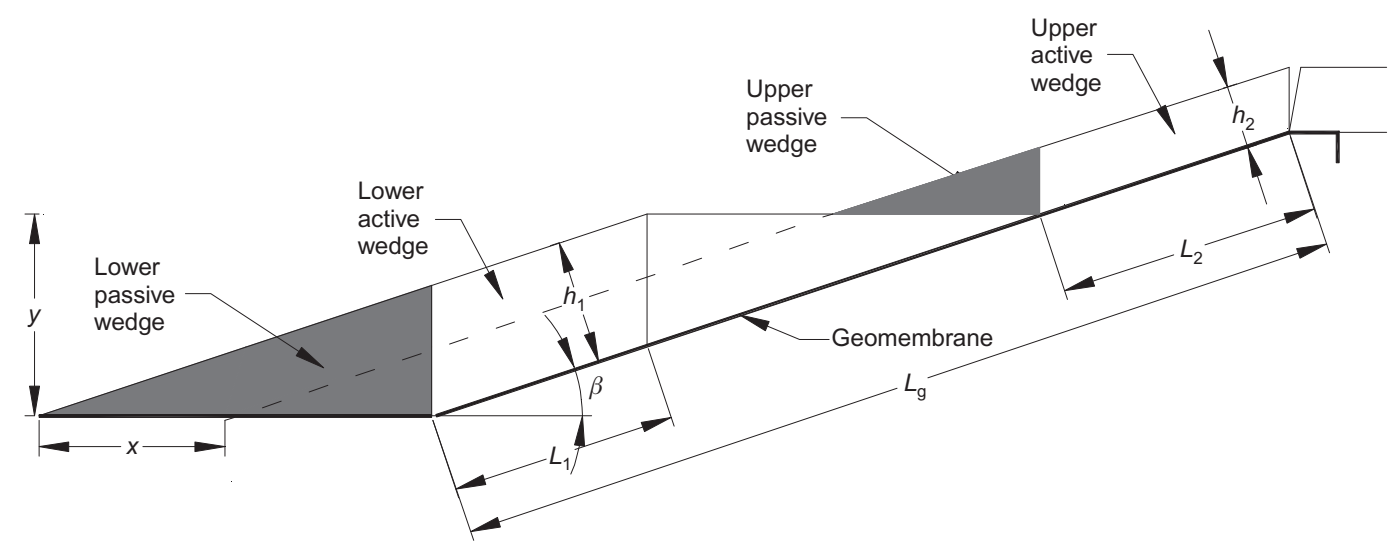

Figure 5. Limit equilibrium of forces for a cover soil with toe buttress 
Table 4. Parameters for toe buttress (all water forces, $U$, are zero)

\begin{tabular}{|l|l|l|l|}
\hline Parameter & Koerner and Soong (2005) $\left(x+\frac{h}{\sin \beta} \leqslant \frac{y}{\tan \beta}\right)$ & $\begin{array}{l}\text { Proposed equation } \\
\text { (lower) }\end{array}$ & $\begin{array}{l}\text { Proposed equation } \\
\text { (upper) }\end{array}$ \\
\hline$W_{\mathrm{A}}$ & $\gamma\left[h_{1}\left(\frac{y}{\sin \beta}-\frac{h_{1}}{\tan \beta}\right)+\frac{h_{1}^{2}}{2 \tan \beta}-\frac{h_{1}^{2} \tan \beta}{2}+h\left(L_{\mathrm{g}}-\frac{y}{\sin \beta}\right)+\frac{h^{2}}{2 \sin \beta}\right]$ & $\gamma h_{1} L_{1}$ & $\gamma h_{2} L_{2}$ \\
$C_{\mathrm{A}}$ & $c_{\mathrm{a}}^{\prime} L_{\mathrm{g}}$ & $c_{\mathrm{a}}^{\prime} L_{1}$ & $c_{\mathrm{a}}^{\prime} L_{2}$ \\
$W_{P}$ & $\frac{\gamma h_{1}^{2}}{\sin 2 \beta}$ & $\frac{\gamma h_{1}^{2}}{\sin (2 \beta)}$ & $\frac{\gamma h_{2}^{2}}{\sin (2 \beta)}$ \\
$C_{\mathrm{P}}$ & $\frac{c^{\prime} h_{1}}{\sin \beta}$ & $\frac{c^{\prime} h_{1}}{\sin \beta}$ & $\frac{c^{\prime}}{\sin \beta}$ \\
\hline
\end{tabular}

minor modification for the change or orientation of the tension crack at the top of the slope, as shown in Figure 6.

For the active wedge,

$$
\begin{aligned}
& X=L_{\mathrm{g}}(\sin \beta-\cos \beta \tan \omega)+\frac{h_{c}}{\cos \beta} \\
& L_{\mathrm{g}}=L-\frac{D}{\sin B}
\end{aligned}
$$

where $\omega$ is the finished slope angle of the cover soil; $D$ is the thickness of the cover soil at the bottom of the landfill, measured perpendicular to the base liner; $h_{\mathrm{c}}$ is the thickness of the cover soil at the crest of the slope, measured perpendicular to the slope; and $X$ is the vertical height of the passive wedge of the tapered cover layer.

The required parameters for the generic analysis are given in Table 5 .

\section{COMPUTATIONAL LIMIT ANALYSIS}

\subsection{Introduction}

The basic geometry of the veneer cover soil model used in CLA analysis is presented in Figure 1. In the model the material below the geomembrane was set as a rigid material, which indicates that no slip-lines are to be modelled in that area, while the geomembrane and cover soil were modelled as Mohr-Coulomb materials. The veneer cover soil was modelled with strength parameters $c^{\prime}$ and $\phi^{\prime}$ and self-weight $\gamma$. The geomembrane was represented by the boundary zone automatically created between the body of veneer cover soil and the rigid layer with shear strength parameters $c_{\mathrm{a}}^{\prime}$ and $\delta^{\prime}$.

In order to force the system into a state of collapse required by limit analysis, an adequacy factor must be applied to one or more disturbing forces. In this work an additional horizontal body force was applied to the system

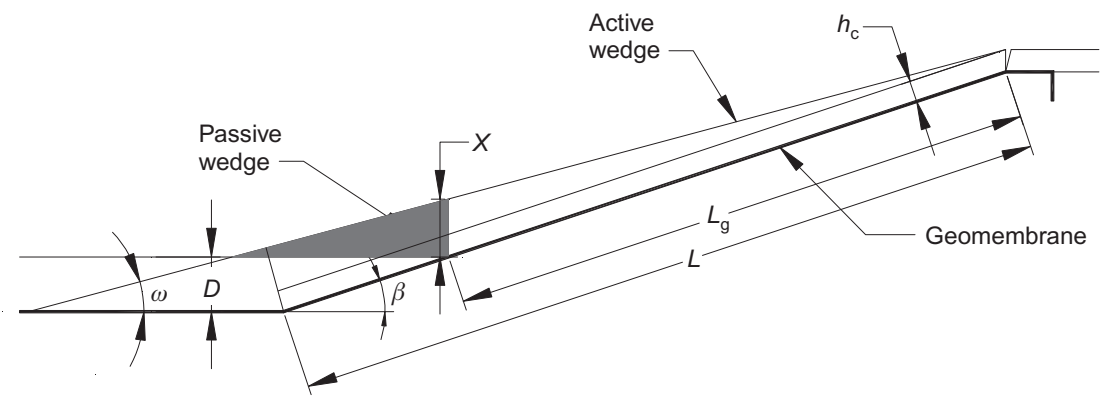

Figure 6. Dimensions of tapered thickness cover soil (after Koerner and Soong 2005)

\begin{tabular}{|c|c|c|c|}
\hline Parameter & \multicolumn{2}{|l|}{ Koerner and Soong (2005) } & Proposed equation \\
\hline$W_{\mathrm{A}}$ & $\gamma\left[\left(L_{\mathrm{g}}-h_{\mathrm{c}} \tan \beta\right)\left(\frac{Y \cos \beta}{2}+h_{\mathrm{c}}\right)+\frac{h_{\mathrm{c}}^{2} \tan \beta}{2}\right]$ & where $Y=X-\frac{h_{c}}{\cos \beta}$ (see Figure 5) & $\gamma L_{g}\left[h_{c}+\frac{X \cos \beta-h_{c}}{2}\right]$ \\
\hline$C_{\mathrm{A}}$ & $c_{\mathrm{a}}^{\prime} L_{\mathrm{g}}$ & & $c_{\mathrm{a}}^{\prime} L_{\mathrm{g}}$ \\
\hline$W_{\mathrm{P}}$ & $\frac{\gamma}{2 \tan \omega} X^{2}$ & & $\frac{\gamma}{2 \tan \omega} X^{2}$ \\
\hline$C$ & $c X$ & & $c X$ \\
\hline$c_{P}$ & $\overline{\tan \omega}$ & & $\overline{\tan \omega}$ \\
\hline
\end{tabular}

Table 5. Parameters for tapered cover soil. All water forces $U$ are zero 
(using the 'seismic' modelling facility in LimitState:GEO) with an adequacy factor applied to it. The original system is just on the point of collapse when the adequacy factor transitions between zero and unstable. Partial factors were applied to $c_{\mathrm{a}}^{\prime}, \tan \delta^{\prime}, c^{\prime}$ and $\tan \phi^{\prime}$. The factor that produces a collapse with an adequacy factor of zero is the FoS on strength for the problem.

The accuracy of the solution depends on the spacing between nodes used in a model. The spacing can be arranged by setting the number of nodes using the nodal density setting. In the studies presented in this paper a fine nodal density was used for all problems, with the exception of the construction equipment problem, where a local soil zone of extent $9 \mathrm{~m}$ beneath the vehicle was defined with a baseline nodal spacing of 0.1 . An example of nodal density distribution is illustrated in Figure 7.

In the case of cover soil with seepage forces, the average pore pressure ratio coefficient $r_{\mathrm{u}}$ was set to $\left(\gamma_{\mathrm{w}} / \gamma_{\mathrm{s}}\right) \cos ^{2} \beta$ to model water pressures corresponding to flow parallel to the slope.

\subsection{Validation}

A check was carried out by modelling the exact limit equilibrium analyses by Koerner and Soong (2005) and the new analyses presented in this paper in CLA software, as shown in Figure 8. The cover soil was replaced by rigid material with the same self-weight. The failure planes were modelled to be exactly the same as described in Koerner and Soong by drawing these in a boundary zone, with strength parameters $c^{\prime} / \mathrm{FoS}$ and $\arctan \left(\tan \phi^{\prime} / \mathrm{FoS}\right)$ applied to the horizontal interface; $c^{\prime}=0, \phi^{\prime}=\beta$ applied to the vertical interface; and $c_{\mathrm{a}}^{\prime} / \mathrm{FoS}$ and $\arctan \left(\tan \delta^{\prime} /\right.$ FoS) applied to the inclined interface.

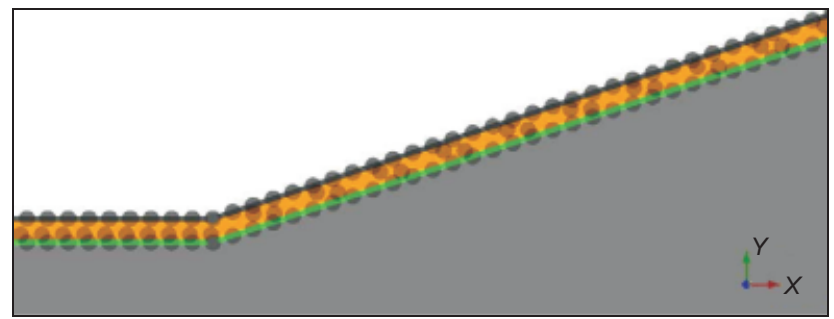

Figure 7. Nodal density for CLA

\section{ELASTO-PLASTIC FINITE-ELEMENT ANALYSIS}

In the FE model, the material below the geomembrane was treated as rigid (scenarios with no seepage forces) or non-porous (scenarios with seepage forces), with rock parameters such that the slip surface failure will not occur in that material but along the interface. The MohrCoulomb model and drained behaviour was adopted for the veneer cover soil.

The interface was modelled using the option 'interface' available in FE software. The interface appears as a dashed line, and can be drawn on both sides of the geometry line, indicating the upper and lower interface. In this analysis the two interfaces have the same parameters, which are presented in the next section. After the FE model geometry was drawn, and material parameters were applied to the obtained clusters, the appropriate boundary conditions were applied to the geometry. The vertical boundaries were fixed in the horizontal direction, and the basal boundary was fixed in both the vertical and horizontal directions. A medium mesh was generated for the whole model. For the cover soil layer a refined cluster option was used to generate a finer mesh in order to gain optimum performance. An example of mesh generation is presented in Figure 9. The model was assumed to be drained: therefore the initial water pressure was generated with a very low water level. The analysis was carried out using a staged construction method. For both seepage conditions the pore water pressure was applied to the veneer soil cluster using interpolation from the adjacent line option. The pore pressure on the surface was set to

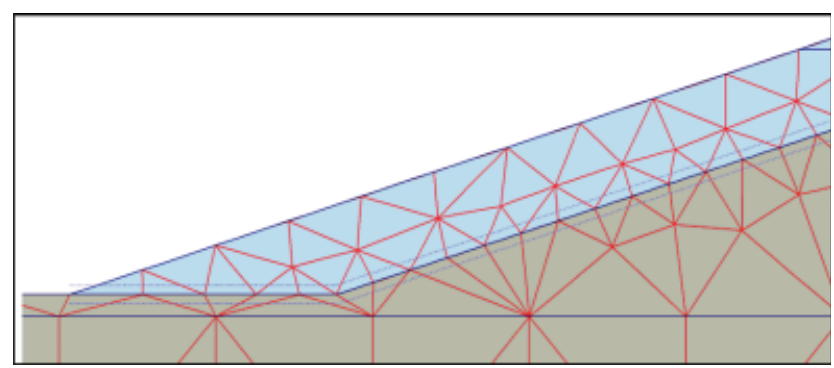

Figure 9. Mesh generation for FE analysis

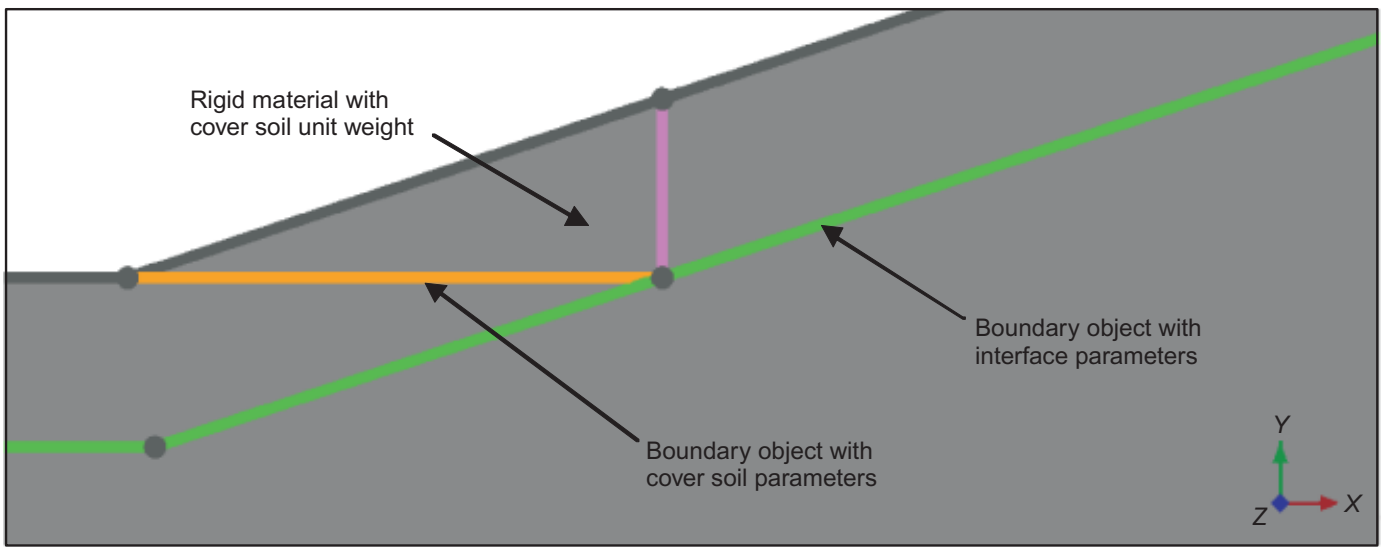

Figure 8. Model geometry for CLA: locked failure plane 
zero and that at the membrane was set to $\gamma_{\mathrm{w}} h_{\mathrm{w}} \cos \beta$ to give the same water pressure distribution as used in the analytical model. The FoS was computed by successively reducing the strength parameters $\tan \phi^{\prime}$ and $c^{\prime}$ of the soils and $c_{\mathrm{a}}^{\prime}$ and $\tan \delta^{\prime}$ of the interfaces until failure of the structure occurred. To define the value of the soil strength parameters at any stage of the analysis, the total multiplier $\Sigma M s f$ is used, given by

$$
\Sigma M s f=\frac{\tan \phi_{\text {input }}^{\prime}}{\tan \phi_{\text {reduced }}^{\prime}}=\frac{c_{\text {input }}^{\prime}}{c_{\text {reduced }}^{\prime}}
$$

In Equation 19, the subscript 'input' refers to the properties of the material inserted into the analysis, and the subscript 'reduced' refers to the value reduced by the program. The value of $\Sigma M s f$ at failure gives the FoS for the analysis undertaken.

$$
\mathrm{FoS}=\frac{\text { available strength }}{\text { strength at failure }}=\text { value of } \Sigma M s f \text { at failure }
$$

An example of the FoS obtained from FE analysis is presented in Appendix A.

\section{ASSESSMENT OF FIELD SCENARIOS: SPECIFICATION AND DIMENSIONS}

In this study, the LE, CLA and FE methods will be compared for typical parameter sets found in landfill engineering in order to highlight essential differences and similarities.

All of the above methods are applied to the simple model geometry presented in Figure 1. The model for the analysis includes a passive wedge at the toe, an active wedge along the slope length, and a tension crack at the crest. A slope angle $\beta$ of $18.4^{\circ}$, thickness of the cover soil $h$ of $300 \mathrm{~mm}$ and length $L_{\mathrm{g}}$ of $30 \mathrm{~m}$ were assumed for all three methods. The thickness of $300 \mathrm{~mm}$ was used by Koerner and Soong (2005), and is used again here to facilitate comparisons. In the tapered model the thickness of the cover at the toe, $D$, was assumed as $1.4 \mathrm{~m}$ (measured perpendicular to the base line) and at the crest the thickness of the soil $h_{\mathrm{c}}$ as $150 \mathrm{~mm}$ (measured perpendicular to the slope). The finished slope angle of the cover soil $\omega$ was adopted as $16^{\circ}$. For the buttress, the toe berm's dimensions were assumed as $x=2 \mathrm{~m}$ and $y=6.8 \mathrm{~m}$ (for details of the geometry refer to Figure 5). For the construction equipment, a vehicle length of $9 \mathrm{~m}$ and weight of $30 \mathrm{kN} / \mathrm{m}$ was investigated.

The analysis was carried out adopting the design engineering parameters for the cover soil and interface provided by Koerner and Soong (2005) and presented in Table 6. Koerner and Soong assumed that only one type of material is placed directly alongside the geomembrane, and that it is cohesionless.

\section{ANALYSIS OF RESULTS AND DISCUSSION}

\subsection{General overview}

The results of the study provide a comparison of the three different methods (LE, LA, and FE) in the form of a minimum global FoS, and are presented in Table 7. Further details of the analyses for the LE methods proposed in this paper are given in Appendix B. In general, all the results show the expected trends. The CLA analysis results for the forced solution matched exactly with those obtained from the proposed LE analysis, which provided cross-validation of the model. The results obtained from the three methods for the uniform veneer cover soil thickness and the tapered thickness problems were very similar (to within $1 \%$ ). This indicates that some of the simplifying assumptions in the LE analysis (e.g. assumption of a tension crack, which would have been correctly modelled as a wedge in the numerical analysis) are reasonable. Other analyses will be discussed in the following sections.

\subsection{Buttress problem}

For the buttress analysis, the numerical results showed that the collapse mechanism was either the upper thin cover layer only, or the buttress layer only, depending on which

\begin{tabular}{|c|c|c|}
\hline Parameters & Cover soil (sand) & Interface \\
\hline $\begin{array}{l}\text { Dry unit weight, } \gamma\left(\mathrm{kN} / \mathrm{m}^{3}\right) \\
\text { Saturated unit weight, } \gamma_{\mathrm{s}}\left(\mathrm{kN} / \mathrm{m}^{3}\right) \\
\text { Cohesion intercept, } c^{\prime}\left(\mathrm{kN} / \mathrm{m}^{2}\right) \\
\text { Angle of shearing resistance, } \phi^{\prime} \text { (degrees) } \\
\text { Young's modulus, } E^{\prime}\left(\mathrm{kN} / \mathrm{m}^{2}\right)^{\mathrm{c}} \\
\text { Poisson's ratio, } v^{\mathrm{c}} \\
\text { Drained adhesion intercept, } c_{\mathrm{a}}^{\prime}\left(\mathrm{kN} / \mathrm{m}^{2}\right) \\
\text { Interface friction angle, } \delta^{\prime} \text { (degrees) }\end{array}$ & $\begin{array}{c}18 \\
21 \\
0^{\mathrm{a}}, 1-0.001^{\mathrm{b}} \\
30 \\
30000 \\
0.2 \\
- \\
-\end{array}$ & $\begin{array}{c}- \\
- \\
- \\
- \\
4845^{\mathrm{d}} \\
0.489 \mathrm{~d} \\
0 \\
22\end{array}$ \\
\hline \multicolumn{3}{|c|}{$\begin{array}{l}\text { a Used in LE and CLA. } \\
\text { b Nominal value (required for FE analysis). See Appendix C for sensitivity analysis. } \\
\text { d Used in FE analysis only. Calculated according to PLAXIS Manual (Brinkgreve et al. 2008). } \\
\text { d Plaxis uses an interface with virtual thickness } t \text {. The given values of Young's modulus } E^{\prime} \text { and } \\
\text { Poisson's ratio } v \text { for the interface were determined from a back-calculation such that they would be } \\
\text { equivalent to a shear interface stiffness } K_{\mathrm{S}} \text { of the order of } 10 \mathrm{MPa} / \mathrm{m} \text { and a normal interface stiffness } \\
K_{\mathrm{N}} \text { of the order of } 450 \mathrm{MPa} / \mathrm{m} \text {. }\end{array}$} \\
\hline
\end{tabular}

Table 6. Model input parameters for all methods 
Table 7. Factor of safety

\begin{tabular}{|c|c|c|c|c|c|c|}
\hline \multirow[t]{3}{*}{ Situation or condition } & \multicolumn{6}{|c|}{ FoS value } \\
\hline & \multicolumn{2}{|c|}{ LE method } & \multicolumn{3}{|c|}{ CLA analysis } & \multirow[t]{2}{*}{ FE analysi } \\
\hline & $\begin{array}{l}\text { Koerner and } \\
\text { Soong }^{\mathrm{a}}\end{array}$ & Current work & $\begin{array}{l}\text { Forced current } \\
\text { LE model }{ }^{\mathrm{b}}\end{array}$ & $\begin{array}{c}\text { Forced current } \\
\text { LE model }\end{array}$ & $\begin{array}{l}\text { Optimal } \\
\text { solution }\end{array}$ & \\
\hline Uniform veneer cover layer & 1.25 & 1.254 & 1.254 & 1.257 & 1.243 & 1.242 \\
\hline Construction equipment & 1.24 & 1.258 & 1.258 & 1.261 & 1.171 & 1.153 \\
\hline Horizontal seepage & 0.94 & 0.684 & 0.684 & 0.719 & 0.684 & 0.682 \\
\hline Seepage parallel to slope & 0.94 & 0.941 & 0.941 & 0.948 & 0.907 & 0.915 \\
\hline Buttress $x=2 \mathrm{~m}, y=6.8 \mathrm{~m}$ & $1.37^{\mathrm{d}}$ & $1.364^{\mathrm{e}}$ & $1.364^{\mathrm{e}}$ & $1.371^{\mathrm{e}}$ & $1.307^{\mathrm{f}}$ & $1.309^{\mathrm{f}}$ \\
\hline Tapered thickness & 1.55 & 1.572 & 1.572 & 1.578 & 1.563 & 1.564 \\
\hline
\end{tabular}

a All results were taken from Koerner and Soong (2005) except for tapered thickness, which was taken from Koerner (2005).

$\mathrm{b}$ The failure plane was forced to be exactly as described in Section 3.2, with $\phi^{\prime}=18.4^{\circ}$ on the active/passive wedge interface.

${ }^{c}$ The failure plane was forced to be exactly as described in Section 3.2, with full $\phi^{\prime}$ acting on the active/passive wedge interface.

${ }^{d}$ The critical failure involved the whole slope.

e The critical failure involved the upper slope.

f The critical failure involved the lower slope (refer to Figures 11 and 12).

was longer. In either case the FoS comes out similar, since each is essentially the same slope mechanism. Inclusion of a buttress layer has only a marginal effect, as noted by Koerner and Soong (2005). This may change if the soil has significant cohesion.

To show the change of the position of the failure mechanism, a sensitivity analysis has been undertaken using the CLA method, examining the variation of FoS with $y$ (see Figure 5). The results are presented in Figure 10 , which shows that an optimal geometry of the buttress can be found to obtain maximum FoS. However, the variation of FoS is unlikely to be large enough to warrant detailed analysis.

In the light of these observations it might be concluded that a tapered slope provides a more efficient use of fill than a buttressed slope. Initial studies using CLA analysis indicate that this is the case. For example, to achieve an FoS of 1.31 for the type of geometry investigated in these cases studies requires $50 \%$ more soil in the buttress than in a tapered slope. However, a more detailed study is beyond the scope of this paper.

As a general observation, the results from the CLA optimal solution analysis and FE analysis are lower then those obtained using the LE method. Figures 11 and 12

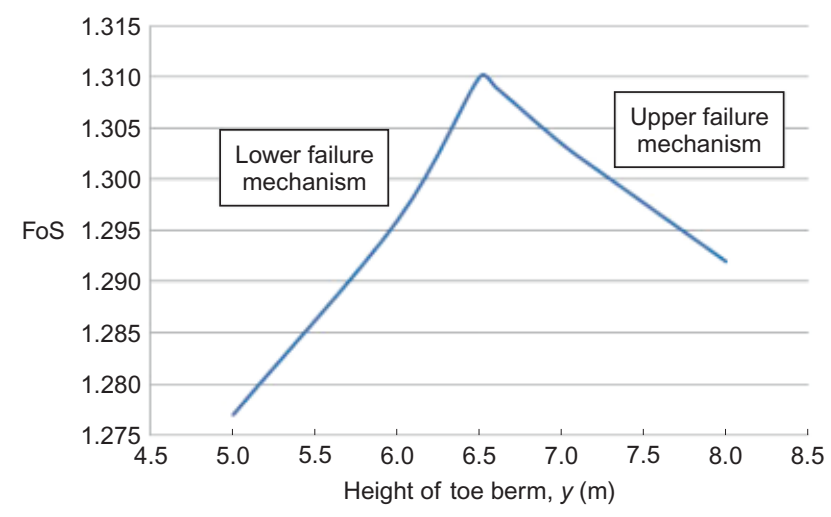

Figure 10. Buttress: upper and lower failure mechanism

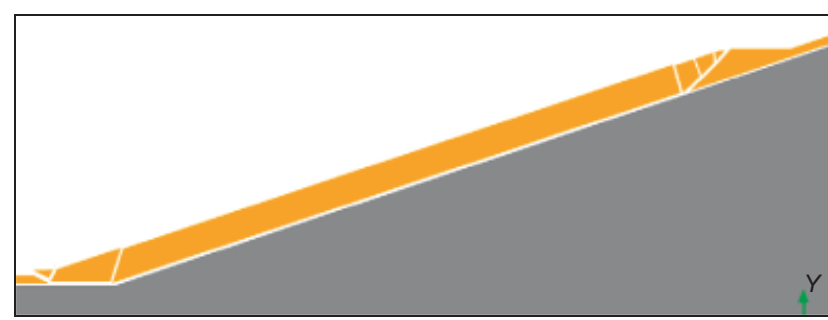

Figure 11. CLA failure plane: buttress (optimal solution; white lines represent slip-lines or pre-existing boundaries)

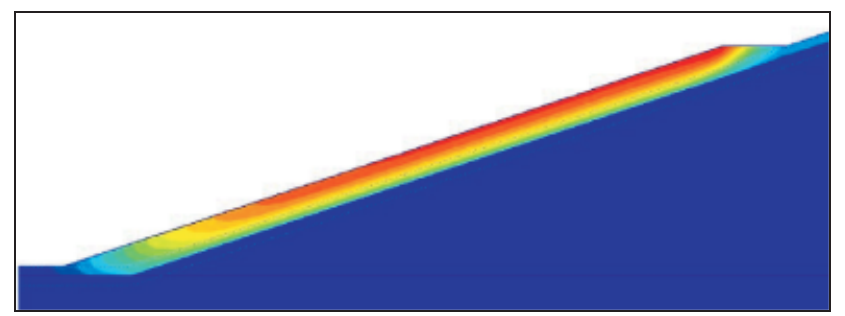

Figure 12. FE analysis failure plane: buttress (contours represent incremental displacements)

show that in those analyses (only the lower buttressed portion is shown) the failure mode involves a deeperseated passive wedge. This indicates that there is a critical value of $D$ (the thickness of horizontal cover soil at the base of the landfill) at which the failure mode switches from the simple LE mechanism to one involving a deeperseated passive wedge that utilises the weaker geomembrane interface at depth. As presented in Figure 11, the failure mechanism in the CLA analysis is represented by a number of slip-lines, whereas in the FE analysis the failure is represented by contours of incremental displacement, which gives an indication of the likely failure mechanism.

A sensitivity study on the effect on $D$ has been performed (refer to Appendix C), which shows that, for a uniform slope and the material parameters considered in 
this paper, the switch from the simple LE failure mechanism to one along the base of the passive wedge occurs when $D$ is equal approximately to 0.6 of the thickness of the cover soil, $h$.

\subsection{Seepage problems}

In the scenario when horizontal seepage was modelled, the Koerner and Soong (2005) LE solution has a value of FoS approximately $40 \%$ higher than the results obtained from the proposed revised LE analysis, CLA and FE analyses. For the original Koerner and Soong LE analysis the failure surface started at the crest and finished at the toe of the slope, whereas the proposed LE analysis assumes that the failure plane starts at the level of the water and finishes at the toe. This assumption was corroborated by the CLA and FE analyses. This type of failure, presented in Figure 13 (CLA analysis) and Figure 14 (FE analysis), would be considered more critical. The FE analysis output is represented by shading of the total displacement increments, which indicates the most applicable failure mechanism of the veneer cover soil.

\subsection{Construction equipment}

The results obtained from the analysis with the construction equipment on the slope show an increased safety factor for the proposed localised LE analysis, whereas in contrast the optimal CLA and the FE analyses showed a reduction in FoS of approximately $8 \%$, but also with a local failure mechanism. Failure mechanisms are presented in Figure 15 (CLA analysis) and Figure 16 (FE analysis), respectively, and indicate not just sliding but also a bearing-capacity-type failure.

These results indicate that a simple LE analysis of the generic type employed in this paper is probably not suitable for analysing this type of problem. Since only frictional problems are considered in this paper, addition of the construction equipment weight in the sliding LE

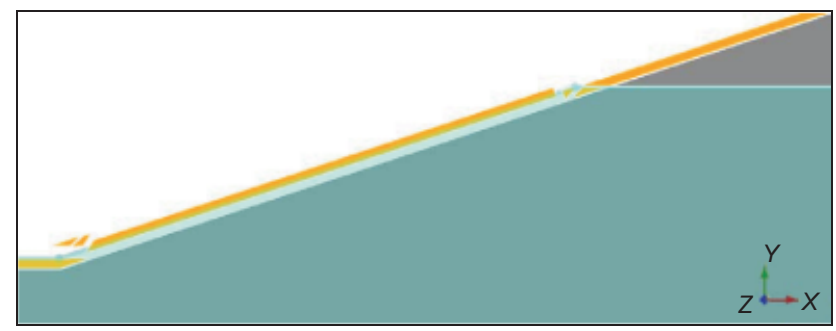

Figure 13. Failure plane in CLA: horizontal seepage forces (displacement of failure soil body magnified greatly)

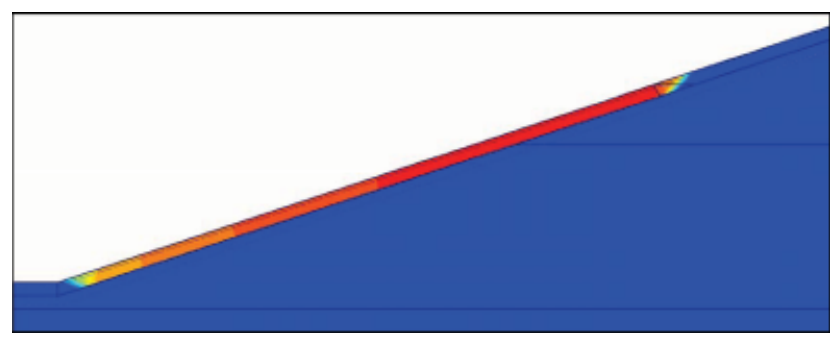

Figure 14. Failure plane in FE analysis: horizontal seepage forces (contours represent incremental displacements)

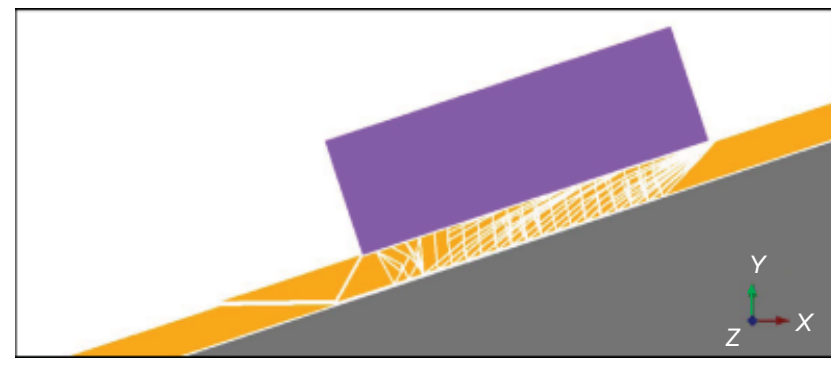

Figure 15. Failure plane in CLA: construction equipment (white lines represent slip-lines or pre-existing boundaries)

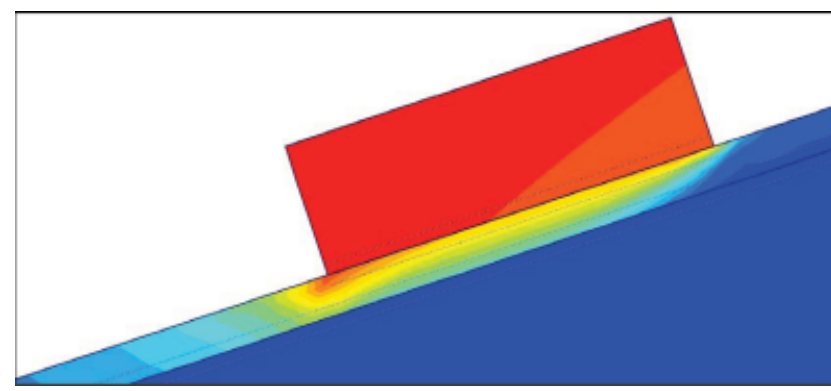

Figure 16. Failure plane in FE analysis: construction equipment (contours represent incremental displacements)

analyses is similar to increasing the length of the slope by an equivalent mass of soil. The FoS would thus be expected to reduce, in comparison with the uniform veneer cover layer, as is seen. However, if only a local LE sliding analysis is undertaken, then the FoS would normally be expected to increase, as is seen also. Although the LE analysis may not be applicable here, the inherent conservatism of a plane-strain analysis is likely to compensate for the overestimate of the FoS by a sliding-only analysis.

\section{PRACTICAL IMPLICATIONS AND USE OF LIMIT EQUILIBRIUM METHODS}

The LE method remains the most commonly adopted method for slope stability analysis. However, it is important to understand the strengths and limitations of the LE method, as for any other method of analysis. The modified LE analyses presented in this paper have been shown to give generally good agreement with those provided by the CLA and FE methods, providing similar factors of safety and failure mechanism patterns. However, the results were generally slightly non-conservative. It is concluded that the LE method is a very useful technique to provide a first estimate for a simple problem. Nevertheless, the method should be used in conjunction with numerical approaches, such as FE analysis or CLA analysis, to make best use of the advantages of both methods. The LE approach provides a useful simple check on the numerical analysis.

One exception to this assessment is the modelling of construction equipment. The numerical approaches indicated that the failure mechanism includes elements of bearing capacity failure not captured by a simple sliding LE analysis, which might as a consequence overestimate the FoS. This effect may become more severe for other geometries not considered in this paper. 
Additionally, caution should be utilised where the cover layer thickness at the base of the landfill (beyond the base of the slope) is small. In such a case, a modified LE (or a CLA or FE) analysis should be used to model deep-seated failure at the slope base (as shown in Figure 11).

\section{CONCLUSIONS}

1. A generally applicable limit equilibrium (LE) analysis that can account for local slope failure has been presented, and compared with LE analyses due to Koerner and Soong (2005) and with computational limit analysis (CLA) and finite-element (FE) analyses.

2. Comparisons of the four analysis types for a typical cover layer geometry indicate the following.

(a) Similar results (to within 1\%) were obtained for scenarios involving a uniform cover layer, and a slope with tapered thickness.

(b) For the problem with seepage parallel to the slope, the FoS was $\sim 4 \%$ lower in the CLA and $\mathrm{FE}$ analyses than in either of the LE analyses.

(c) For the buttressed problem the FoS was $\sim 6 \%$ lower in the CLA and FE analyses than in either of the LE analyses. It was shown that failure could occur in the lower (buttressed part of the) slope or the upper slope. Depending on the geometry, the failure mode could also involve deeper-seated failure at the base of the slope.

(d) For the horizontal seepage scenario, the FoS was $\sim 40 \%$ lower for the proposed LE analysis, and in the CLA and FE analyses, compared with the Koerner and Soong LE analysis. In this case local slope failure is critical.

(e) For the construction equipment problem, the FoS from the CLA and FE analyses was $\sim 8 \%$ lower than the Koerner and Soong LE analysis, and indicated that local failure was critical. However, the proposed local LE analysis gave higher results than the Koerner and Soong LE analysis. The CLA and FE analyses indicated that the failure mechanism includes elements of bearing capacity failure not captured by a simple sliding LE analysis, which might as a consequence overestimate the FoS. A numerical analysis is thus recommended in this case.

3. The above conclusions indicate that the modified LE analysis proposed in this paper is an easy-to-use method that can provide a good first approximation for the failure mechanism and FoS for the simple problems of veneer cover slope stability. For more complex geometries, this LE method should be used in conjunction with numerical approaches such as CLA or FE analysis.

\section{ACKNOWLEDGEMENTS}

The first author wishes to express her great appreciation to Dr K. Mawire from Mott MacDonald Ltd for his support during the FE analysis.

\section{NOTATION}

Basic SI units are given in parentheses.

$a$ upslope acceleration $\left(\mathrm{m} / \mathrm{s}^{2}\right)$

$C_{\mathrm{A}}$ cohesive shear force per unit width between cover soil of active wedge and geomembrane $(\mathrm{N} / \mathrm{m})$

$C_{\mathrm{P}} \quad$ cohesive shear force per unit width along failure plane of passive wedge $(\mathrm{N} / \mathrm{m})$

$c^{\prime}$ drained cohesion intercept of cover soil and other materials $\left(\mathrm{N} / \mathrm{m}^{2}\right)$

$c_{\mathrm{a}}^{\prime}$ drained adhesion intercept between cover soil of active wedge and geomembrane $\left(\mathrm{N} / \mathrm{m}^{2}\right)$

$c_{\text {mob }}^{\prime}$ mobilised drained cohesion intercept of cover soil $\left(\mathrm{N} / \mathrm{m}^{2}\right)$

$D$ thickness of cover soil at bottom of landfill, measured perpendicular to base liner $(\mathrm{m})$

$E^{\prime}$ Young's modulus $\left(\mathrm{N} / \mathrm{m}^{2}\right)$

$E_{\mathrm{A}}^{\prime}$ effective interwedge force per unit width acting on active wedge from passive wedge $(\mathrm{N} / \mathrm{m})$

$E_{\mathrm{P}}^{\prime} \quad$ effective interwedge force per unit width acting on passive wedge from active wedge $(\mathrm{N} / \mathrm{m})$

FoS factor of safety (dimensionless)

$g$ acceleration due to gravity $\left(\mathrm{m} / \mathrm{s}^{2}\right)$

$H$ vertical height of slope measured from toe $(\mathrm{m})$

$H_{\mathrm{w}} \quad$ vertical height of free water surface measured from toe $(\mathrm{m})$

$h$ thickness of cover soil (m)

$h_{1}$ thickness of lower section of buttressed slope $(\mathrm{m})$

$h_{2}$ thickness of upper section of buttressed slope (m)

$h_{\mathrm{c}}$ thickness of cover soil at crest of slope, measured perpendicular to slope (m)

$h_{\mathrm{w}}$ height of free water surface measured in direction perpendicular to slope (m)

$L \quad$ length of slope measured along geomembrane $(\mathrm{m})$

$L_{1}$ length of lower active wedge of toe buttress $(\mathrm{m})$

$L_{2}$ length of upper active wedge of toe buttress $(\mathrm{m})$

$L_{\mathrm{c}} \quad$ length of slope involved in LE mechanism under construction equipment $(\mathrm{m})$

$L_{\mathrm{g}} \quad$ length of slope involved in LE mechanism measured along geomembrane $(\mathrm{m})$

$L_{\mathrm{w}} \quad$ length of slope involved in LE mechanism under water surface $(\mathrm{m})$

$l$ length of construction equipment (m)

$M$ mass of construction equipment per unit width $(\mathrm{kg} / \mathrm{m})$

$N^{\prime} \quad$ effective normal force per unit width $(\mathrm{N} / \mathrm{m})$

$N_{\mathrm{A}}^{\prime}$ effective force per unit width normal to failure plane of active wedge $(\mathrm{N} / \mathrm{m})$

$N_{\mathrm{P}}^{\prime} \quad$ effective force per unit width normal to failure plane of passive wedge $(\mathrm{N} / \mathrm{m})$ 
$r_{\mathrm{u}} \quad$ average pore pressure ratio coefficient (dimensionless)

$T$ effective shear force between construction equipment and cover fill $(\mathrm{N} / \mathrm{m})$

$U_{\mathrm{a}}$ resultant of water pressures acting on vertical crack at crest of slope $(\mathrm{N} / \mathrm{m})$

$U_{\mathrm{h}}$ resultant of pore pressure acting on interwedge surfaces $(\mathrm{N} / \mathrm{m})$

$U_{\mathrm{n}}$ resultant of pore pressure acting perpendicular to slope $(\mathrm{N} / \mathrm{m})$

$U_{\mathrm{V}}$ resultant of vertical pore pressure acting on passive wedge $(\mathrm{N} / \mathrm{m})$

$W$ weight of construction equipment $(\mathrm{N} / \mathrm{m})$

$W_{\mathrm{A}}$ total weight of active wedge per unit width $(\mathrm{N} / \mathrm{m})$

$W_{\mathrm{P}}$ total weight of passive wedge per unit width $(\mathrm{N} / \mathrm{m})$

$X$ vertical height of passive wedge of tapered cover layer $(\mathrm{m})$

$x \quad$ width of toe berm (m)

$y$ height of toe berm (m)

$\beta$ soil slope angle beneath geomembrane (degrees)

$\delta^{\prime} \quad$ interface friction angle between cover soil and geosynthetic (degrees)

$\gamma$ dry unit weight of cover soil and other materials $\left(\mathrm{N} / \mathrm{m}^{3}\right)$

$\gamma_{\mathrm{s}}$ saturated unit weight of cover soil and other materials $\left(\mathrm{N} / \mathrm{m}^{3}\right)$

$\gamma_{\mathrm{w}}$ unit weight of water $\left(\mathrm{N} / \mathrm{m}^{3}\right)$

$v$ Poisson's ratio (dimensionless)

$\phi^{\prime}$ angle of shearing resistance of cover soil (degrees)

$\phi_{\text {mob }}^{\prime}$ mobilised angle of shearing resistance of the cover soil (degrees)

$\omega$ finished slope angle of cover soil (degrees)

$\Sigma M s f$ total multiplier used in PLAXIS for computation of factor of safety (dimensionless)

\section{APPENDIX A: FoS FROM FE ANALYSIS}

As already described in Section 4, the factor of safety is defined as the value of $\Sigma M s f$ at failure. The recommended way to evaluate the FoS is to plot the total multiplier $\Sigma M s f$ against a displacement, as shown in the example below in Figure 17. Although the actual displacement values plotted are not relevant for the evaluation of the FoS, they indicate whether the failure mechanism has developed. The figure indicates that the failure mechanism has developed fully, and a more or less constant value of FoS was obtained. For a detailed description of the evaluation of the FoS see the PLAXIS Manual (Brinkgreve et al. 2008).

\section{APPENDIX B: LIMIT EQUILIBRIUM ANALYSIS: CURRENT METHOD}

Calculated values used to obtain the results presented in Column 2 of Table 7 are as presented in Table 8 .

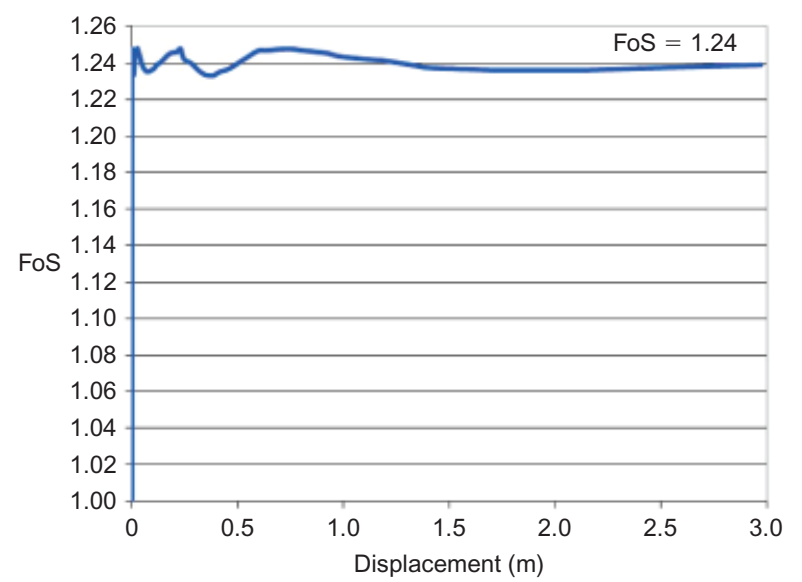

Figure 17. Evaluation of FoS in FE analysis: normal

Table 8. Limit equilibrium analysis

\begin{tabular}{|c|c|c|c|c|c|c|c|}
\hline Model & $\begin{array}{l}\text { Uniform } \\
\text { thickness }\end{array}$ & $\begin{array}{l}\text { Construction } \\
\text { equipment on } \\
\text { slope }\end{array}$ & $\begin{array}{l}\text { Horizontal } \\
\text { seepage }\end{array}$ & $\begin{array}{l}\text { Seepage parallel } \\
\text { to slope }\end{array}$ & $\begin{array}{c}\text { Buttress bottom } \\
\text { layer }(x=2 \mathrm{~m}, \\
y=6.8 \mathrm{~m})\end{array}$ & $\begin{array}{c}\text { Buttress top layer } \\
(x=2 \mathrm{~m}, \\
y=6.8 \mathrm{~m})\end{array}$ & $\begin{array}{c}\text { Tapered } \\
\text { thicknesses }\end{array}$ \\
\hline$W_{\mathrm{A}}(\mathrm{kPa})$ & 156.87 & 142.14 & 94.50 & 175.50 & 309.01 & 40.54 & 312.16 \\
\hline$C_{\mathrm{a}}(\mathrm{kPa})$ & 0.00 & 0.00 & 0.00 & 0.00 & 0.00 & 0.00 & 0.00 \\
\hline$N_{\mathrm{a}}(\mathrm{kPa})$ & 148.85 & 134.87 & 47.78 & 124.64 & 293.21 & 38.46 & 296.20 \\
\hline$U_{\mathrm{n}}(\mathrm{kPa})$ & 0.00 & 0.00 & 41.89 & 41.89 & 0.00 & 0.00 & 0.00 \\
\hline$U_{\mathrm{h}}(\mathrm{kPa})$ & 0.00 & 0.00 & 0.44 & 0.11 & 0.00 & 0.00 & 0.00 \\
\hline$U_{\mathrm{a}}(\mathrm{kPa})$ & 0.00 & 0.00 & 0.44 & 0.11 & 0.00 & 0.00 & 0.00 \\
\hline$W_{\mathrm{P}}(\mathrm{kPa})$ & 2.70 & 2.70 & 3.16 & 2.82 & 26.06 & 2.70 & 50.76 \\
\hline$C_{\mathrm{P}}(\mathrm{kPa})$ & 0.00 & 0.00 & 0.00 & 0.00 & 0.00 & 0.00 & 0.00 \\
\hline$U_{\mathrm{v}}(\mathrm{kPa})$ & 0.0 & 0.00 & 1.33 & 0.33 & 0.00 & 0.00 & 0.0 \\
\hline$a$ & 46.98 & 42.57 & 28.75 & 52.67 & 92.55 & 12.14 & 93.50 \\
\hline$b$ & -67.65 & -61.44 & -24.81 & -59.31 & -145.23 & -18.64 & -160.82 \\
\hline$c$ & 10.96 & 9.93 & 3.52 & 9.18 & 21.59 & 2.83 & 21.81 \\
\hline FoS & 1.254 & 1.258 & 0.684 & 0.941 & 1.403 & 1.364 & 1.572 \\
\hline
\end{tabular}




\section{APPENDIX C: SENSITIVITY ANALYSIS}

\section{C.1. Effect of value of $c^{\prime}$ in $F E$ analysis}

PLAXIS is able to model cohesionless sands $\left(c^{\prime}=0\right)$, but some analyses may not perform well in these cases. To avoid complications in the FE analysis, particularly when the analysed soil layer reaches the ground surface, the PLAXIS Manual (Brinkgreve et al. 2008) suggests using a small value for effective cohesion. Typically a nominal value of $c^{\prime}=0.1 \mathrm{kN} / \mathrm{m}^{2}$ is often used. This may lead to a tensile strength that may be unrealistic for soils, but the tension cut-off option may be used to reduce this. In order to assess the impact of the value of $c^{\prime}$ on the results, a sensitivity analysis was undertaken. Figure 18 illustrates the relative influence of the cohesion value on the FoS in the FE analysis, and indicates significant sensitivity. In this research, therefore, the cohesion of the veneer cover soil and interface was assumed as $0.001 \mathrm{kN} / \mathrm{m}^{2}$. This did not lead to any problems with the numerical analyses.

\section{C.2. Effect of value of $D$ on mechanism type}

A sensitivity study on the effect of the thickness of horizontal soil cover at the base of the landfill, $D$, on the FoS and failure mechanism has been performed by varying the value of $D$ in the uniform slope scenario. The results of the analysis are presented in Figure 19, and indicate

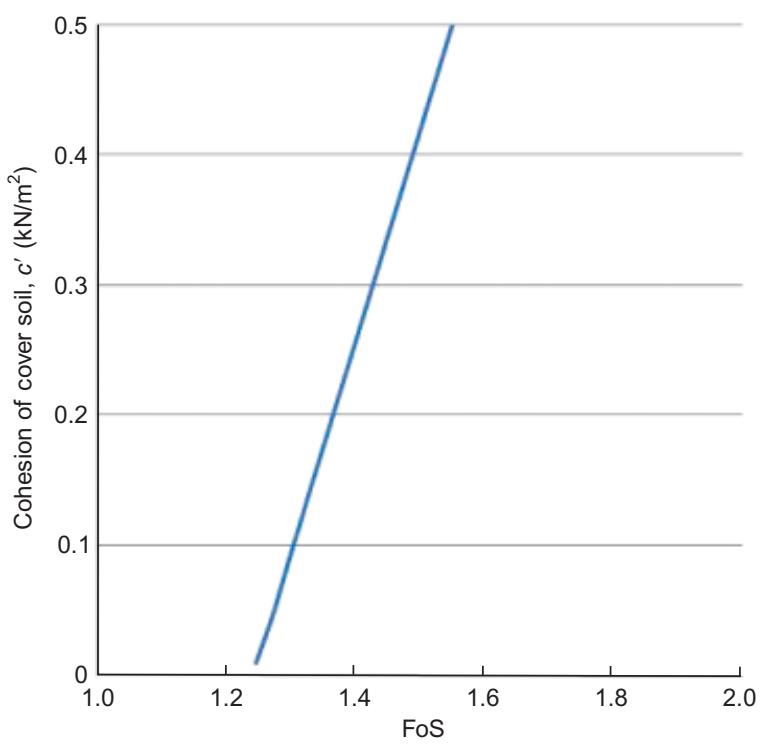

Figure 18. Effect of value of $c^{\prime}$ in $F E$ analysis

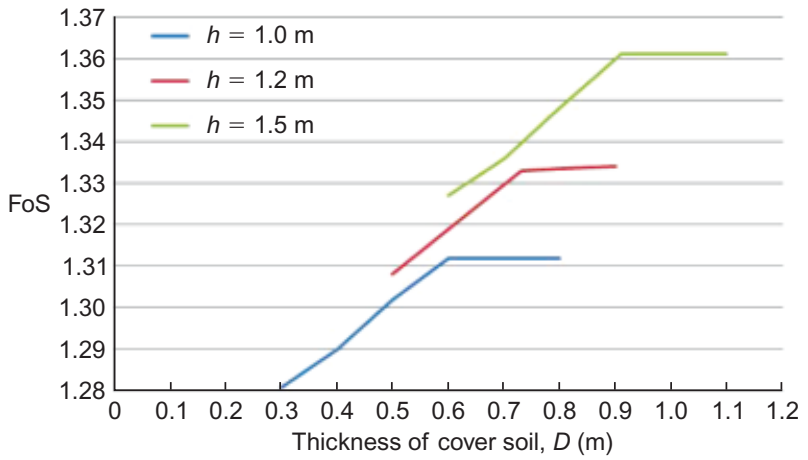

Figure 19. Effect of value of $D$ on uniform veneer cover soil analysis

that for a uniform slope the switch from the simple LE failure mechanism (presented in Figure 1) to one along the base of the passive wedge can be determined by the ratio of $D$ to $h$, where $h$ is the thickness of the cover soil. This ratio can be expressed as follows: $D=x h$, where $x=f\left(\phi^{\prime}, \delta^{\prime}\right)$. For the parameters used in this analysis $\left(\phi^{\prime}=30^{\circ}, \delta^{\prime}=22^{\circ}\right)$, the value of $x$ is 0.6 . Since this ratio relates to the resistance of the passive wedge only, it would be expected to apply for all values of $h$.

\section{REFERENCES}

Brinkgreve, R. B. J., Broere, W. \& Waterman, D. (2008). PLAXIS 2D:Version 9. 0 Reference Manual, PLAXIS, Netherlands.

Giroud, J. P. \& Beech, J. F. (1989). Stability of soil layers on geosynthetics lining systems. Proceedings of the Geosynthetics ' 89 Proceedings, San Diego, CA, USA, Vol. 1, pp. 35-46.

Jones, D. R. V. \& Dixon, N. (1998). Stability of geosynthetic lining systems. Proceedings of the Symposium on Geotechnical Engineering of Landfills, Nottingham, UK, Dixon, N., Murray, E. J. and Jones, D. R. V., Editors, Thomas Telford, London, pp. 99-117.

Koerner, R. M. (2005). Designing with Geosynthetics, Prentice Hall, Upper Saddle River, NJ, USA, pp. 490-500.

Koerner, R. M. \& Hwu, B.-L. (1991). Stability and tension considerations regarding cover soils on geomembrane lined slopes. Geotextiles and Geomembranes, 10, No. 4, 335-355.

Koerner, R. M. \& Soong, T.-Y. (2005). Analysis and design of veneer cover soils. Geosynthetics International, 12, No. 1, 28-49.

Smith, C. \& Gilbert, M. (2007). Application of discontinuity layout optimization to plane plasticity problems. Proceedings of the Royal Society A: Mathematical, Physical \& Engineering Sciences 463, No. 2086, 2461-2484.

LimitState Ltd (2009). Limitstate: Geo manual version 2. 0, LimitState, Sheffield.

Soong, T.-Y. \& Koerner, R. M. (1996). Seepage induced slope instability. Geotextiles and Geomembranes, 14, No. 7/8, 425-445.

The Editor welcomes discussion on all papers published in Geosynthetics International. Please email your contribution to discussion@geosynthetics-international.com by 15 October 2012. 